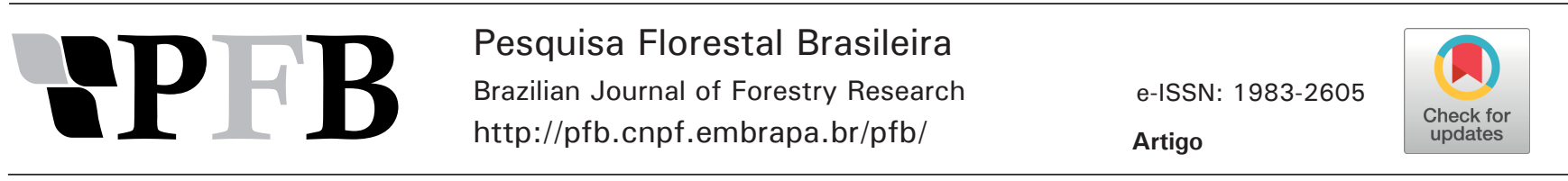

\title{
Propriedades de painéis aglomerados produzidos com madeiras de Ligustrum lucidum e Pinus taeda
}

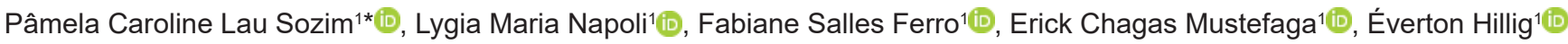 \\ ${ }^{1}$ Universidade Estadual do Centro-Oeste, PR 153, Km 7, Riozinho, CEP 84500-000, Irati, PR, Brasil
}

*Autor correspondente:

pamela.lau@hotmail.com

Termos para indexação:

Alfeneiro do Japão

Propriedades da madeira

Chapas de madeira

Index terms:

Broad-leaf privet

Wood properties

Wood panels

Histórico do artigo:

Recebido em 14/08/2018

Aceito em 22/02/2019

Publicado em 10/05/2019

doi: 10.4336/2019.pfb.39e201801696

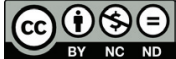

Trabalho apresentado no V Seminário de Atualização Florestal, 24 e 28 de setembro de 2018, Irati, PR.
Resumo - Este trabalho teve por objetivo avaliar as propriedades físicas e mecânicas de painéis aglomerados produzidos com madeira de Ligustrum lucidum W.T. Aiton, pura ou com Pinus taeda, e comparar as propriedades desses painéis com os requisitos normativos e com os produzidos somente com Pinus taeda. Os painéis foram produzidos com adesivos uréia-formaldeído e tanino-formaldeído na proporção de $10 \%$ de massa de sólido sobre a massa seca de partículas. Para a confecção dos painéis, foi estabelecida massa específica nominal de $0,75 \mathrm{~g} \mathrm{~cm}^{-3}$, pressão específica de $3,92 \mathrm{MPa}$, temperatura de $160{ }^{\circ} \mathrm{C}$ e tempo de prensagem de 8 min para o adesivo uréia-formaldeído e 10 min para tanino-formaldeído. Após o período de climatização dos painéis, foram confeccionados os corpos de prova destinados aos ensaios físicos e mecânicos. Verificou-se que apenas madeira de Ligustrum lucidum com adesivo tanino-formaldeído, bem como a combinação de madeiras e adesivo uréia-formaldeído, proporcionou aos painéis melhores propriedades físicas e mecânicas. Esses tipos de painéis atenderam aos requisitos normativos de propriedades mecânicas e demonstraram que L. lucidum tem potencial para uso na produção de painéis aglomerados.

\section{Properties of particleboard made with Ligustrum Iucidum and Pinus taeda woods}

\begin{abstract}
This study aimed to evaluated physical and mechanical properties of particleboard manufactured with Ligustrum lucidum wood, pure or with Pinus taeda, and to compare these panels properties with the normative requirements and those panels produced only with Pinus taeda. Panels were produced with urea-formaldehyde and tannin-formaldehyde resins, in $10 \%$ of proportion based on solid mass of dried particles. For the panels preparation, it was established nominal specific mass of 0.75 g.cm ${ }^{-3}$, specific pressure of $3.92 \mathrm{MPa}$, temperature of $160{ }^{\circ} \mathrm{C}$ and pressing time of 8 min for urea-formaldehyde resin and $10 \mathrm{~min}$ for tannin-formaldehyde. After the air conditioning period, samples for physical and mechanical tests were prepared. The use of only Ligustrum lucidum wood and tannin-formaldehyde, as well as the use of mixture woods and urea-formaldehyde provided panels better performance in relation to physical and mechanical properties. These panels reached mechanical properties requirements of normative codes and demonstrated the potential of L. lucidum for particleboard production.
\end{abstract}




\section{Introdução}

Em 2016, o Brasil totalizou a produção de 7,3 milhões de $\mathrm{m}^{3}$ de painéis reconstituídos, sendo três milhões de painéis aglomerados, produzidos principalmente na região Sul do país e nos Estados de São Paulo e Minas Gerais (Indústria Brasileira de Árvores, 2017).

A confecção dos painéis aglomerados é sustentada por matéria-prima proveniente de reflorestamentos de Pinus spp. e, em menor escala, de Eucalyptus spp. Porém, pesquisas mostram a viabilidade técnica de produção de painéis aglomerados com espécies nativas e exóticas, de baixa e alta massa específica, pura ou em mistura com as espécies tradicionalmente já utilizadas, com desempenho físico-mecânico que atendem aos requisitos da norma brasileira NBR14810-2 (Associação Brasileira de Normas Técnicas, 2013). Além disso, para madeiras de alta massa específica, sua mistura com madeiras de baixa massa específica tem demonstrado vantagens, pois permite a produção de painéis menos densos e com propriedades mecânicas satisfatórias (Iwakiri et al., 2010; Trianoski et al., 2011; Sanches et al., 2016). Moslemi (1974) afirma que as espécies com massa específica de até $0,55 \mathrm{~g} \mathrm{~cm}^{-3}$ são as mais adequadas para a produção de painéis aglomerados, pois proporcionam painéis mais leves, com taxa de compactação adequada.

Bianche et al. (2012) destacam que a utilização de madeira de outras espécies na composição dos painéis aglomerados é uma alternativa que pode proporcionar menor custo e uma produção sustentável, mas o uso intensificado da madeira como matéria-prima para fins industriais ou construtivos só pode ocorrer a partir do conhecimento adequado de suas propriedades, sejam elas físicas, químicas ou mecânicas (Gonçalves et al., 2009).

Ligustrum lucidum, popularmente conhecida como alfeneiro ou ligustro, é uma espécie exótica originária da China, que foi muito utilizada em arborização urbana no Brasil, sendo hoje considerada uma espécie invasora (Emer et al., 2013). A espécie apresenta quantidade considerável de indivíduos no dossel da Floresta Ombrófila Mista, onde seu incremento é maior que de algumas espécies nativas, conforme relatado por Kanieski et al. (2017).

É uma espécie de rápido crescimento, que atinge cerca de $10 \mathrm{~m}$ de altura, podendo ser cultivada em todo território brasileiro, pois se desenvolve em vários tipos de solo e diferentes regimes de temperatura e umidade, além de apresentar tolerância à sombra e ser resistente à poda rústica (Lorenzi et al., 2003; Ditomaso et al., 2013).
Pouco se conhece sobre as propriedades e as características da madeira dessa espécie. Vale et al. (2005) obtiveram $0,56 \mathrm{~g} \mathrm{~cm}^{-3}$ de massa específica básica para galhos de Ligustrum lucidum provenientes da poda urbana em Brasília, DF. Esses autores também realizaram a análise imediata e a carbonização da madeira, concluindo que os galhos desta espécie apresentam características favoráveis tanto para o uso como lenha, quanto para a produção de carvão vegetal. Todavia, destaca-se que a utilização desta espécie para produção de painéis aglomerados ainda não foi investigada.

Segundo Johnson (2009), L. lucidum foi muito plantada na Austrália para arborização urbana, como cerca-viva ou para fazer sombra, tornando-se posteriormente uma espécie exótica invasora, semelhante ao que ocorreu no Brasil. $\mathrm{O}$ autor destaca ainda que as espécies de Ligustrum invadem muitos ecossistemas naturais, alterando a diversidade e abundância de espécies nativas, de plantas ou animais.

Para se controlar e corrigir os equívocos decorrentes da introdução de uma espécie exótica numa região é importante que se conheça as características dessa espécie, bem como de seu potencial de utilização. Diante deste cenário, o presente trabalho teve como objetivo avaliar o desempenho físico-mecânico de painéis aglomerados produzidos com madeira das espécies Ligustrum lucidum W.T. Aiton e Pinus taeda L., usadas puras e misturadas.

\section{Material e métodos}

Para a confecção dos painéis, utilizou-se madeira de Pinus taeda e Ligustrum lucidum, obtidas de três árvores de cada espécie, colhidas ao acaso na região de Irati, PR. Das árvores, foram retirados toras e discos. Com os discos se determinou a massa específica aparente, com base na norma NBR11941 (Associação Brasileira de Normas Técnicas, 2003). As toras foram desdobradas em tábuas e posteriormente foram processadas em plaina desempenadeira, para a obtenção de partículas do tipo flake. Essas partículas foram moídas em moinho de martelos, para obtenção de partículas tipo sliver, usadas para produção dos painéis aglomerados. As partículas passaram por peneiras de 6 e 12 mesh e foram encaminhadas à estufa com ventilação forçada, a $60{ }^{\circ} \mathrm{C}$, onde permaneceram até atingirem cerca de $3 \%$ de umidade (base seca), valor recomendado pelos fabricantes do adesivo para a adequada adesão entre as partículas. 
Os painéis foram produzidos utilizando partículas de madeira de $P$. taeda $(\mathrm{Pt})$ e $L$. lucidum (Ll), puras e em mistura, nas quais foi adicionado o adesivo uréiaformaldeído (UF) ou tanino-formaldeído (TF) (Tabela 1), na proporção de $10 \%$ de massa de sólido do adesivo sobre a massa seca de partículas, configurando um delineamento inteiramente casualizado em esquema fatorial com seis tratamentos e duas repetições por tratamento, conforme apresentado na Tabela 2.

Tabela 1. Características dos adesivos usados para a fabricação de painéis aglomerados com madeira de Pinus taeda e Ligustrum lucidum.

Table 1. Characteristics of the adhesives used for the manufacture of particleboard with wood of Pinus taeda and Ligustrum lucidum.

\begin{tabular}{ccc}
\hline \multirow{2}{*}{ Característica } & \multicolumn{2}{c}{ Adesivo } \\
\cline { 2 - 3 } & Uréia-formaldeído $^{1}$ & Tanino-formaldeído $^{2}$ \\
\hline \multirow{2}{*}{ Matéria-prima } & Petróleo & $\begin{array}{c}\text { Acacia mearnsii De } \\
\text { Wild. }\end{array}$ \\
Cor & Leitosa-branca & Marrom-escuro \\
pH & $7,6-8,2$ & $6,6-6,9$ \\
Viscosidade (cP) & $300-400$ & $100-200^{*}$ \\
Teor de sólidos $(\%)$ & 68 & 45 \\
\hline
\end{tabular}

Nota: *Viscosidade para o teor de sólidos utilizado de 45\%. Fonte: ${ }^{1}$ Momentive Química do Brasil (2012); ${ }^{2}$ Tanac \& Phenotan (2014).

Tabela 2. Delineamento experimental usado para a avaliação de painéis aglomerados com madeira de Pinus taeda e Ligustrum lucidum.

Table 2. Experimental design for the evaluation of particleboard with wood of Pinus taeda and Ligustrum lucidum.

\begin{tabular}{cccc}
\hline \multirow{2}{*}{ Tratamento } & Adesivo & \multicolumn{2}{c}{$\begin{array}{c}\text { Proporção de partículas } \\
\text { (\%) }\end{array}$} \\
& & P. taeda & L. lucidum \\
\hline 1 & Uréia-formaldeído & 100 & --- \\
2 & Uréia-formaldeído & --- & 100 \\
3 & Uréia-formaldeído & 50 & 50 \\
4 & Tanino-formaldeído & 100 & --- \\
5 & Tanino-formaldeído & --- & 100 \\
6 & Tanino-formaldeído & 50 & 50 \\
\hline
\end{tabular}

Para a confecção dos painéis, foi estabelecida massa específica nominal de $0,75 \mathrm{~g} \mathrm{~cm}^{-3}$, pressão específica de $3,92 \mathrm{MPa}$, temperatura de $160^{\circ} \mathrm{C}$ e tempo de prensagem de 8 min para o adesivo uréia-formaldeído e 10 min para tanino-formaldeído.
Após a prensagem, os painéis permaneceram em câmara climatizada com umidade relativa de $65 \pm 5 \%$ e temperatura de $20 \pm 3{ }^{\circ} \mathrm{C}$, até atingirem umidade de equilíbrio higroscópico. Ao término deste período, foram produzidos corpos de prova destinados aos ensaios físicos e mecânicos (Tabela 3), conforme as recomendações da norma ASTM D 1037-06a (American Society for Testing and Materials, 2006), bem como a razão de compactação resultante (Maloney, 1993). Foram também determinadas a massa específica aparente e a umidade médias da madeira, de 16 cunhas com ângulo de $30^{\circ}$ amostradas para cada espécie, de acordo com a norma NBR7190 (Associação Brasileira de Normas Técnicas, 1997).

Tabela 3. Ensaios físicos e mecânicos dos painéis aglomerados.

Table 3. Physical and mechanical tests of particleboard.

\begin{tabular}{|c|c|c|}
\hline Ensaio & $\begin{array}{l}\text { Dimensões } \\
(\mathrm{cm})\end{array}$ & $\begin{array}{l}\text { Número de } \\
\text { corpos de } \\
\text { prova por } \\
\text { tratamento }\end{array}$ \\
\hline Massa específica aparente & $5 \times 5 \times 1,3$ & 6 \\
\hline Teor de umidade & $5 \times 5 \times 1,3$ & 6 \\
\hline $\begin{array}{l}\text { Absorção de água (períodos de } 2 \text { e } \\
24 \text { h de imersão em água) }\end{array}$ & $15 \times 15 \times 1,3$ & 6 \\
\hline $\begin{array}{l}\text { Inchamento em espessura } \\
\text { (períodos de } 2 \text { e } 24 \text { h de imersão } \\
\text { em água), }\end{array}$ & $15 \times 15 \times 1,3$ & 6 \\
\hline $\begin{array}{l}\text { Flexão estática (módulos de } \\
\text { elasticidade e de ruptura) }\end{array}$ & $36,3 \times 7,6 \times 1,3$ & 6 \\
\hline $\begin{array}{l}\text { Tração perpendicular à superfície } \\
\text { do painel }\end{array}$ & $5 \times 5 \times 1,3$ & 6 \\
\hline $\begin{array}{l}\text { Arrancamento de parafuso de } \\
\text { superfície }\end{array}$ & $10,2 \times 7,6 \times 2,6$ & 6 \\
\hline Arrancamento de parafuso de topo & $15,2 \times 7,6 \times 1,3$ & 6 \\
\hline
\end{tabular}

A análise estatística, em esquema fatorial, foi efetuada para verificar a influência do fator adesivo e do fator espécie. A normalidade dos dados foi analisada pelo teste de Kolmogorov Smirnov e a homogeneidade das variâncias pelo teste de Bartlett. Quando comprovada a homogeneidade das variâncias, foi feita análise de variância (ANOVA), sendo as médias comparadas por meio do teste de Tukey, nos casos de rejeição da hipótese de igualdade pela ANOVA. Quando necessário, foi realizada a transformação Box-Cox dos dados. As análises estatísticas foram efetuadas ao nível de 5\% de probabilidade.

Para análise da interação entre fatores e para comparação com os requisitos normativos, foram determinados os valores médios de cada propriedade 
por tipo de painel, que foram comparados aos requisitos das normas EN312 (European Committee for Standardization, 2003) e NBR14810-2 (Associação Brasileira de Normas Técnicas, 2006, 2013).

\section{Resultados}

A massa específica aparente da madeira de Ligustrum lucidum foi aproximadamente o dobro do valor da madeira de Pinus taeda, apesar da umidade de equilíbrio menor. Os valores médios de massa específica dos painéis alcançaram o valor nominal somente para os produzidos com a mistura das espécies e com adesivo de uréia-formaldeído, mas não apresentaram diferença estatística dos demais tipos de painéis. A umidade de equilíbrio dos painéis também foi semelhante. A utilização da madeira pura de L. lucidum, ou em mistura $\operatorname{com} P$. taeda, levou à redução da razão de compactação dos painéis (Tabela 4).

Os valores médios das propriedades físicas e mecânicas dos painéis variaram entre as espécies para inchamento em espessura, módulo de elasticidade (MOE) e módulo de ruptura (MOR) em flexão estática, arrancamento de parafuso no topo e ligação interna. Para o fator adesivo, houve diferença somente para inchamento em espessura, MOR e MOE em flexão estática e ligação interna. A interação entre esses dois fatores foi significativa para inchamento por $24 \mathrm{~h}, \mathrm{MOR}$, MOE, arrancamento de parafuso na superfície e no topo e ligação interna (Tabela 5).

Tabela 4. Propriedades físicas da madeira de Pinus taeda e Ligustrum lucidum e dos painéis aglomerados produzidos com as duas espécies e com os adesivos uréia-formaldeído e tanino-formaldeído.

Table 4. Physical properties of Pinus taeda and Ligustrum lucidum wood and of particleboard manufactured with two species and urea-formaldehyde and tannin-formaldehyde adhesives.

\begin{tabular}{|c|c|c|c|c|c|c|c|c|}
\hline \multirow{2}{*}{ Painel } & \multirow[t]{2}{*}{ Ad } & \multicolumn{2}{|c|}{$\begin{array}{c}\text { Proporção de } \\
\text { partículas (\%)* }\end{array}$} & \multirow{2}{*}{$\begin{array}{l}\text { Massa específica da } \\
\text { madeira }\left(\mathrm{g} \mathrm{cm}^{-3}\right)\end{array}$} & \multirow{2}{*}{$\begin{array}{r}\text { Umidade da } \\
\text { madeira (\%) }\end{array}$} & \multirow{2}{*}{$\begin{array}{c}\text { Massa específica } \\
\text { dos painéis }\left(\mathrm{g} \mathrm{cm}^{-3}\right)\end{array}$} & \multirow{2}{*}{$\begin{array}{c}\text { Umidade dos } \\
\text { painéis }(\%)\end{array}$} & \multirow{2}{*}{$\begin{array}{c}\text { Razão de } \\
\text { compactação } \\
\text { dos painéis }\end{array}$} \\
\hline & & $\mathbf{P t}$ & LI & & & & & \\
\hline 1 & UF & 100 & --- & 0,38 & 16,6 & $0,70 \mathrm{a}$ & $11,3 \mathrm{a}$ & $1,84 \mathrm{a}$ \\
\hline 2 & UF & --- & 100 & 0,74 & 15,0 & $0,73 \mathrm{a}$ & $10,0 \mathrm{a}$ & $0,99 \mathrm{~d}$ \\
\hline 3 & UF & 50 & 50 & 0,56 & 15,8 & $0,75 \mathrm{a}$ & $10,6 \mathrm{a}$ & $1,34 \mathrm{~b}$ \\
\hline 4 & $\mathrm{TF}$ & 100 & --- & 0,38 & 16,6 & $0,70 \mathrm{a}$ & $9,0 \mathrm{a}$ & $1,84 \mathrm{a}$ \\
\hline 5 & $\mathrm{TF}$ & --- & 100 & 0,74 & 15,0 & $0,70 \mathrm{a}$ & $9,6 \mathrm{a}$ & $0,95 \mathrm{~d}$ \\
\hline 6 & $\mathrm{TF}$ & 50 & 50 & 0,56 & 15,8 & $0,66 \mathrm{a}$ & $9,6 \mathrm{a}$ & $1,18 \mathrm{c}$ \\
\hline
\end{tabular}

Notas: Ad - Adesivo; *com base na massa seca; UF - uréia-formaldeído; TF - tanino-formaldeído; Pt - Pinus taeda; Ll - Ligustrum lucidum.

Tabela 5. Valores médios das propriedades físicas e mecânicas dos painéis aglomerados produzidos com madeira de Pinus taeda e Ligustrum lucidum e com os adesivos uréia-formaldeído e tanino-formaldeído, para os fatores tipo de adesivo e espécie de madeira.

Table 5. Mean values of physical and mechanical properties of the particleboard manufactured with Pinus taeda and Ligustrum lucidum wood and urea-formaldehyde and tannin-formaldehyde adhesives, for factors adhesive type and wood species.

\begin{tabular}{|c|c|c|c|c|c|c|c|c|c|c|}
\hline \multirow{2}{*}{\multicolumn{2}{|c|}{ Fator / Nível }} & \multicolumn{2}{|c|}{ Absorção de água } & \multicolumn{2}{|c|}{$\begin{array}{c}\text { Inchamento em } \\
\text { espessura }\end{array}$} & \multicolumn{2}{|c|}{ Flexão estática } & \multicolumn{2}{|c|}{ Arrancamento de parafuso } & \multirow{2}{*}{$\begin{array}{c}\text { Ligação interna } \\
\text { RTper (MPa) }\end{array}$} \\
\hline & & 2 h (\%) & 24 h (\%) & $2 \mathrm{~h}(\%)$ & 24 h $(\%)$ & $\begin{array}{l}\text { MOR } \\
\text { (MPa) }\end{array}$ & $\begin{array}{l}\text { MOE } \\
\text { (GPa) }\end{array}$ & Rsup (MPa) & Rtop (MPa) & \\
\hline \multirow{2}{*}{ Ad } & $\mathrm{UF}$ & $9,92 \mathrm{a}$ & $80,60 \mathrm{a}$ & $6,34 b$ & $23,22 b$ & $19,25 \mathrm{a}$ & $2,85 \mathrm{a}$ & $1079,71 \mathrm{a}$ & $978,33 \mathrm{a}$ & $0,64 \mathrm{a}$ \\
\hline & $\mathrm{TF}$ & $10,09 \mathrm{a}$ & $86,50 \mathrm{a}$ & $12,15 \mathrm{a}$ & $34,79 \mathrm{a}$ & $16,23 b$ & $2,59 b$ & $1040,46 a$ & $967,11 \mathrm{a}$ & $0,49 b$ \\
\hline \multirow{3}{*}{ Es } & $\mathrm{Pt}$ & $8,20 \mathrm{a}$ & $89,44 a$ & $10,79 \mathrm{a}$ & $38,14 \mathrm{a}$ & $11,72 \mathrm{c}$ & $1,74 \mathrm{c}$ & $1076,96 \mathrm{ab}$ & $901,63 a$ & $0,45 b$ \\
\hline & $\mathrm{Ll}$ & $11,82 \mathrm{a}$ & $83,14 a$ & $6,84 \mathrm{~b}$ & $16,73 b$ & $27,36 a$ & $3,89 \mathrm{a}$ & $1006,93 b$ & $1044,62 \mathrm{a}$ & $0,63 \mathrm{a}$ \\
\hline & $\mathrm{Pt}+\mathrm{Ll}$ & $10,00 \mathrm{a}$ & $78,07 \mathrm{a}$ & $10,11 \mathrm{ab}$ & $32,14 \mathrm{a}$ & $14,14 \mathrm{~b}$ & $2,53 b$ & $1246,37 \mathrm{a}$ & $971,91 \mathrm{a}$ & $0,61 \mathrm{a}$ \\
\hline \multicolumn{2}{|c|}{ Interação } & $0,16^{\mathrm{ns}}$ & $1,52^{\mathrm{ns}}$ & $0,06^{\text {ns }}$ & $4,34 *$ & $76,88^{*}$ & $129,90 *$ & $47,37 *$ & $7,51^{*}$ & $370,60 *$ \\
\hline
\end{tabular}

Notas: Ad - adesivo; Es - espécie; UF - uréia-formaldeído; TF - tanino-formaldeído; Pt - Pinus taeda; L1 - Ligustrum lucidum; MOR - módulo de ruptura; MOE - módulo de elasticidade; Rsup - resistência ao arrancamento de parafuso de superfície; Rtop - resistência ao arrancamento de parafuso de topo; RTper - resistência à tração perpendicular à superfície do painel. Médias seguidas de uma mesma letra em uma mesma coluna não diferem estatisticamente entre si pelo Teste de Tukey ao nível de $5 \%$ de probabilidade. ${ }^{\text {ns }}=$ não significativo; $*=$ significativo a $5 \%$ de probabilidade pelo teste Tukey. 
Na Tabela 6 são apresentados os valores médios verificados por tipo de painel produzido. Esses valores foram utilizados para análise da interação entre os fatores, quando essa foi significativa, e também para comparação das propriedades dos painéis com os requisitos normativos.

Tabela 6. Valores médios das propriedades físicas e mecânicas dos painéis aglomerados produzidos com madeira de Pinus taeda e Ligustrum lucidum e com os adesivos uréia-formaldeído e tanino-formaldeído.

Table 6. Mean values of physical and mechanical properties of the particleboard manufactured with Pinus taeda and Ligustrum lucidum wood and urea-formaldehyde and tannin-formaldehyde adhesives.

\begin{tabular}{|c|c|c|c|c|c|c|c|c|c|c|c|}
\hline \multirow{2}{*}{$\mathbf{P}$} & \multirow{2}{*}{ Es } & \multirow{2}{*}{ Ad } & \multicolumn{2}{|c|}{ Absorção de água } & \multicolumn{2}{|c|}{$\begin{array}{c}\text { Inchamento em } \\
\text { espessura }\end{array}$} & \multicolumn{2}{|c|}{ Flexão Estática } & \multicolumn{2}{|c|}{ Arrancamento de parafuso } & \multirow{2}{*}{$\begin{array}{l}\text { Ligação interna } \\
\text { RTper (MPa) }\end{array}$} \\
\hline & & & $2 \mathrm{~h}(\%)$ & 24 h (\%) & $2 \mathrm{~h}(\%)$ & 24 h $(\%)$ & $\begin{array}{l}\text { MOR } \\
\text { (MPa) }\end{array}$ & $\begin{array}{l}\text { MOE } \\
\text { (GPa) }\end{array}$ & Rsup (MPa) & Rtop (MPa) & \\
\hline 1 & $\mathrm{Pt}$ & UF & $8,75 \mathrm{a}$ & $90,02 \mathrm{a}$ & $7,21 \mathrm{a}$ & $31,47 \mathrm{ab}$ & $7,58 \mathrm{e}$ & $0,87 \mathrm{e}$ & $1109,12 b$ & $873,01 \mathrm{ab}$ & $0,65 b$ \\
\hline 2 & $\mathrm{Ll}$ & UF & $11,61 \mathrm{a}$ & $82,34 a$ & $5,40 \mathrm{a}$ & $19,16 b$ & $30,49 a$ & $4,41 \mathrm{a}$ & $539,80 \mathrm{c}$ & $899,20 \mathrm{ab}$ & $0,43 \mathrm{c}$ \\
\hline 3 & $\mathrm{Pt}+\mathrm{Ll}$ & UF & $9,41 \mathrm{a}$ & $69,45 \mathrm{a}$ & $6,41 \mathrm{a}$ & $19,03 b$ & $19,69 \mathrm{c}$ & $3,27 b$ & $1590,21 \mathrm{a}$ & $1162,79 \mathrm{ab}$ & $0,84 \mathrm{a}$ \\
\hline 4 & $\mathrm{Pt}$ & $\mathrm{TF}$ & $7,65 \mathrm{a}$ & $88,86 \mathrm{a}$ & $14,36 a$ & $44,81 \mathrm{a}$ & $15,86 \mathrm{~d}$ & $2,62 \mathrm{c}$ & $895,54 b$ & $930,26 \mathrm{ab}$ & $0,25 \mathrm{~d}$ \\
\hline 5 & $\mathrm{Ll}$ & $\mathrm{TF}$ & $12,04 \mathrm{a}$ & $83,95 \mathrm{a}$ & $8,27 \mathrm{a}$ & $14,31 b$ & $24,24 b$ & $3,37 b$ & $1474,06 \mathrm{a}$ & $1190,05 \mathrm{a}$ & $0,84 \mathrm{a}$ \\
\hline 6 & $\mathrm{Pt}+\mathrm{Ll}$ & $\mathrm{TF}$ & $10,59 a$ & $86,69 a$ & $13,82 \mathrm{a}$ & $45,25 \mathrm{a}$ & $8,59 \mathrm{e}$ & $1,79 \mathrm{~d}$ & $902,52 b$ & $781,03 b$ & $0,38 \mathrm{c}$ \\
\hline
\end{tabular}

Notas: P - Painel; Ad - adesivo; Es - espécie; UF - uréia-formaldeído; TF - tanino-formaldeído; Pt - Pinus taeda; L1 - Ligustrum lucidum; MOR - módulo de ruptura; $\mathrm{MOE}$ - módulo de elasticidade; Rsup - resistência ao arrancamento de parafuso de superfície; Rtop - resistência ao arrancamento de parafuso de topo; RTper - resistência à tração perpendicular à superfície do painel. Médias seguidas de uma mesma letra em uma mesma coluna não diferem estatisticamente entre si pelo Teste de Tukey ao nível de 5\% de probabilidade.

\section{Discussão}

A busca por matéria-prima alternativa para a produção de painéis aglomerados, madeira de espécies de rápido crescimento e competidora tem sido relatada na literatura. Sanches et al. (2016) concluíram que Mimosa scabrella e Hovenia dulcis (massa específica de 0,59 e $0,58 \mathrm{~g} \mathrm{~cm}^{-}$ ${ }^{3}$, respectivamente) ainda não são utilizadas em escala industrial, porém, foram consideradas adequadas para a fabricação de painéis aglomerados quando em misturas com espécies de menor massa específica. A madeira de Ligustrum lucidum apresentou massa específica aparente de $0,74 \mathrm{~g} \mathrm{~cm}^{-3}$ (Tabela 4), sendo esta superior a $0,55 \mathrm{~g}$ $\mathrm{cm}^{-3}$ recomendado por Moslemi (1974), com o intuito de se obter painéis com boa razão de compactação e peso apropriado. De modo geral, o aumento na razão de compactação dos painéis causa aumento de sua resistência e rigidez (Trianoski et al., 2013). No entanto, essas propriedades dependem também da massa específica da madeira e de outros fatores.

Todos os painéis confeccionados (Tabela 4) classificam-se como de média massa específica, de acordo com a norma CS 236-66 (Commercial Standard, 1968). Para a variável massa específica aparente dos painéis, os valores médios foram estatisticamente semelhantes entre si e inferiores à massa específica nominal estabelecida em $0,75 \mathrm{~g} \mathrm{~cm}^{-3}$, com exceção dos painéis de uréia-formaldeído e a mistura de espécies. Isso foi atribuído à perda de material durante a formação do painel e retorno em espessura após a prensagem (Trianoski et al., 2013).

As médias de absorção de água obtidas para os painéis confeccionados com tanino-formaldeído foram equivalentes às dos painéis de uréia-formaldeído, porém, foram maiores para inchamento em espessura $2 \mathrm{~h}$ e $24 \mathrm{~h}$ (Tabela 5). Como nesse caso está se avaliando somente o fator adesivo, atribuiu-se maior inchamento dos painéis de tanino-formaldeído aos menores valores obtidos para esse adesivo na resistência à tração perpendicular (ligação interna). Carneiro et al. (2009) obtiveram resultados semelhantes para a propriedade inchamento em espessura quando produziram painéis aglomerados utilizando a madeira de Pinus elliottii e os adesivos uréia-formaldeído e tanino-formaldeído obtido de Anadenanthera peregrina, ambos na proporção de $8 \%$.

Não foi observada diferença de absorção de água entre os diferentes tipos de painéis produzidos em função da composição de espécies (Tabela 5). No entanto, os painéis fabricados com madeira de L. lucidum apresentaram menores valores de inchamento em espessura após períodos de 2 e 24 h de imersão em água. Nesse caso, a menor taxa de compactação dos painéis produzidos 
com madeira de L. lucidum é que ocasionou menor inchamento em espessura.

Verificou-se que a diferença de inchamento em espessura após $24 \mathrm{~h}$ de imersão entre os painéis produzidos com as diferentes espécies de madeira foi maior para o adesivo tanino-formaldeído (Tabela 6), fato relacionado à maior diferença de ligação interna que ocorreu entre as espécies com esse adesivo. Além da relação entre as duas propriedades, os resultados podem diferir, em função da espécie utilizada. A relação entre a ligação interna e o inchamento em espessura também foi verificada por Carvalho et al. (2014) que obtiveram menores valores de ligação interna e maior inchamento em espessura para painéis confeccionados com madeira de Pinus caribaea e adesivo tanino-formaldeído obtido de acácia negra do que para os painéis colados com uréia-formaldeído. Por outro lado, Melo et al. (2010) verificaram maiores valores de ligação interna e menores valores de inchamento em espessura para o adesivo tanino-formaldeído do que para o adesivo de uréia, quando utilizaram madeira de Eucayptus grandis.

De acordo com Moslemi (1974), os painéis com maior razão de compactação apresentam maior inchamento em espessura, devido à maior liberação das tensões de compressão resultantes da prensagem. Fato este observado para os painéis confeccionados com a madeira de . taeda com ambos os adesivos (Tabela 6).

A norma EN 312 (European Committee for Standardization, 2003) determina até $8 \%$ de absorção de água após 2 h de imersão e as normas NBR 14810-2 (Associação Brasileira de Normas Técnicas, 2013) e CS 236-66 (Commercial Standard, 1968) especificam 18\% e $35 \%$ de inchamento em espessura após $24 \mathrm{~h}$ de imersão, respectivamente. Os valores médios obtidos para estas propriedades somente atenderam esses requisitos para os painéis de $P$. taeda e tanino-formaldeído quanto à absorção de água por $2 \mathrm{~h}$, e para inchamento em espessura após $24 \mathrm{~h}$ de imersão. Todos os tratamentos produzidos com o adesivo uréia-formaldeído e os painéis de L. lucidum e tanino-formaldeído atenderam à norma CS 236-66 (Commercial Standard, 1968), mas apenas o tratamento composto por L. lucidum e taninoformaldeído alcançou o valor mínimo requerido pela norma NBR14810-2 (Associação Brasileira de Normas Técnicas, 2013). Os valores de absorção de água por $2 \mathrm{~h}$ de imersão dos outros tipos de painéis foram semelhantes estatisticamente. Para inchamento em espessura por $24 \mathrm{~h}$ de imersão, os painéis produzidos com L. lucidum e com a mistura de espécies, colados com uréia-formaldeído também apresentaram resultados semelhantes (Tabela 6). Napoli et al. (2013) verificaram que a composição dos painéis de Pinus taeda colados com uréia-formaldeído em três camadas diminuiu o inchamento em espessura em relação aos painéis homogêneos. Dessa forma, pressupõe-se melhor desempenho em inchamento dos painéis em três camadas, que são produzidos em escala industrial, do que os painéis homogêneos produzidos neste estudo.

Para as propriedades mecânicas, os painéis fabricados com adesivo uréia-formaldeído apresentaram maiores valores de módulo de elasticidade (MOE) e módulo de ruptura (MOR), quando comparados com os confeccionados com tanino-formaldeído. Também se constatou diferença destas propriedades para o fator espécie, no qual a madeira de L. lucidum se destaca com maiores valores médios. Os painéis produzidos com L. lucidum apresentaram maior resistência e rigidez, mesmo com uma baixa taxa de compactação (Tabela5).

Carvalho et al. (2014) obtiveram a mesma tendência de resultados apresentados nesta pesquisa para a propriedade de MOR em flexão estática. Os autores confeccionaram painéis aglomerados com madeira de Pinus caribaea var. caribaea e adesivos uréiaformaldeído e tanino-formaldeído, obtido de Acacia mearnsii, e relataram que o uso do adesivo tânico levou à redução da resistência dos painéis.

Todos os painéis produzidos (Tabela 6), com exceção de P. taeda e uréia-formaldeído e a mistura de espécies com o adesivo tanino-formaldeído, atenderam aos requisitos das normas EN 312 (European Committee for Standardization, 2003) (MOR $\geq 13 \mathrm{MPa}$ e $\mathrm{MOE} \geq 1,6$ GPa), NBR 14810-2 (Associação Brasileira de Normas Técnicas, 2013) (MOR $\geq 11 \mathrm{MPa}$ e $\mathrm{MOE} \geq 1,8 \mathrm{GPa})$ e CS 236-66 (Commercial Standard, 1968) (MOR $\geq 10,98$ MPa e MOE 2,4 $\geq \mathrm{GPa}$ ).

A resistência ao arrancamento de parafuso, de superfície e de topo, foi superior nos painéis com madeira de L. lucidum e adesivo tanino-formaldeído, ou quando misturada com a madeira de P. taeda e adesivo uréia-formaldeído (Tabela 6). Os painéis produzidos com P. taeda e a mistura de espécies com uréia-formaldeído, como também os de L. lucidum com tanino-formaldeído, atenderam aos requisitos de resistência para a propriedade arrancamento de parafuso, conforme estabelecido pela norma NBR 14810-2 (Associação Brasileira de Normas Técnicas, 2006). As normas EN 312 (European 
Committee for Standardization, 2003), NBR 14810-2 (Associação Brasileira de Normas Técnicas, 2013) e CS 236-66 (Commercial Standard, 1968) estabelecem os requisitos de $\geq 0,35 \mathrm{MPa}, \geq 0,40 \mathrm{Mpa} \mathrm{e} \geq 0,48 \mathrm{MPa}$, respectivamente, para ligação interna, os quais foram atendidos pelos painéis confeccionados com o adesivo uréia-formaldeído e L. lucidum com tanino-formaldeído.

A madeira de L. lucidum e uréia-formaldeído, ou a mesma em mistura com $P$. taeda colada com taninoformaldeído, proporcionou melhor ligação interna nos painéis. Verificou-se que houve uma forte interação entre os fatores adesivo e espécie, e que se refletiu nas demais propriedades físicas e mecânicas. Quando usada uréiaformaldeído, a mistura de espécies e o uso da madeira de $P$. taeda proporcionaram painéis com melhores propriedades. Por outro lado, quando foi usado taninoformaldeído os painéis produzidos com L. lucidum apresentaram as melhores propriedades. De modo geral, esse fato foi atribuído à sinergia entre a massa específica da madeira (ou da mistura) e as características dos adesivos, em especial sua viscosidade. Sendo a solução de uréia-formaldeído mais viscosa que a de taninoformaldeído (Momentive Química do Brasil, 2012; Tanac \& Phenotan, 2014), houve pouca absorção deste adesivo por parte da madeira de L. lucidum, prejudicando o "ancoramento" e a colagem. Por outro lado, houve absorção excessiva do adesivo tanino-formaldeído pela madeira de $P$. taeda e pela mistura de madeiras, o que também causou falha na colagem.

\section{Conclusões}

A utilização da madeira de Ligustrum lucidum pura e o adesivo tanino-formaldeído, ou em mistura com Pinus taeda e o adesivo uréia-formaldeído, proporcionou painéis com melhores propriedades mecânicas e que atenderam aos requisitos normativos de propriedades mecânicas, quando comparado a painéis apenas $\operatorname{com} P$. taeda. Em ambos os casos, foram também verificados os menores valores de absorção de água e inchamento em espessura. Dessa forma, os resultados demonstram que a madeira de L. lucidum pode ser utilizada na produção de painéis aglomerados com ambos os adesivos, sendo que para uréia-formaldeído sua utilização em mistura $\operatorname{com} P$. taeda proporcionou painéis com melhores propriedades físicas e mecânicas.

\section{Referências}

American Society for Testing and Materials. ASTM D 1037-06a: standard test methods for evaluating properties of woo-base fiber and particle panel materials. Philadelphia, 2006.

Associação Brasileira de Normas Técnicas. NBR 7190: projeto de estruturas de madeira. Rio de Janeiro, 1997.

Associação Brasileira de Normas Técnicas. NBR 11941: madeira: determinação da massa específica básica. Rio de Janeiro, 2003.

Associação Brasileira de Normas Técnicas. NBR 14810-2: chapas de madeira aglomerada: parte 2: requisitos. São Paulo, 2006.

Associação Brasileira de Normas Técnicas. NBR 14810-2: painéis de partículas de média massa específica: parte 2: requisitos e métodos de ensaio. São Paulo, 2013.

Bianche, J. J. et al. Propriedades de painéis aglomerados fabricados com partículas de eucalipto (Eucalyptus urophylla), paricá (Schizolobium amazonicum) e vassoura (Sida spp.). Cerne, v. 18, n. 4, p. 623-630, 2012. DOI: 10.1590/S0104-77602012000400012.

Carneiro, A. C. O. et al. Propriedades de chapas de aglomerado fabricadas com adesivo tânico de angico-vermelho (Anadenanthera peregrina) e uréia-formaldeído. Revista Árvore, v. 33, n. 3, p. 521531, 2009. DOI: 10.1590/S0100-67622009000300014.

Carvalho, A. G. et al. Avaliação de adesivos à base de taninos de Pinus caribaea var. bahamensis e de Acacia mearnsii na fabricação de painéis aglomerados. Ciência Florestal, v. 24, n. 2, p. 479-489, 2014. DOI: $10.5902 / 1980509814588$.

Commercial Standard. CS 236-66: mat formed wood particleboard. Geneva, 1968.

Ditomaso, J. M. et al. Weed control in natural areas in the western United States. California: University of California, Weed Research and Information Center, 2013. 544 p.

Emer, A. A. et al. Avaliação quantitativa e qualitativa da arborização do bairro Santa Terezinha na cidade de Pato Branco (PR). Ambiência, v. 9, n. 1, p. 129-143, 2013. DOI: 10.5777/ambiencia.2013.01.09.

European Committee for Standardization. EN 312: particleboards: specifications. Bruxelas, 2003.

Gonçalves, F. G. et al. Estudo de algumas propriedades mecânicas da madeira de um híbrido clonal de Eucalyptus urophylla x Eucalyptus grandis. Revista Árvore, v. 33, n. 3, p. 501-509, 2009. DOI: 10.1590/ S0100-67622009000300012.

Indústria Brasileira de Árvores. Relatório Ibá 2017. Brasília, DF, $2017.80 \mathrm{p}$.

Iwakiri, S. et al. Avaliação do potencial de utilização da madeira de Schizolobium amazonicum "Paricá" e Cecropia hololeuca "Embaúba" para produção de painéis aglomerados. Acta Amazonica, v. 40, n. 2, p. 303-308, 2010. DOI: 10.1590/S0044-59672010000200008.

Johnson, S. B. Privet species' are we sitting on species time bombs? In: BIENNIAL NSW WEEDS CONFERENCE, 15., 2009, Narrabri. Proceedings... Narrabri: [s.n.], 2009. 
Kanieski, M. R. et al. Parâmetros climáticos e incremento diamétrico de espécies florestais em Floresta Aluvial no Sul do Brasil. Floresta e Ambiente, v. 24, e00124814, 2017. DOI: 10.1590/21798087.124814 .

Lorenzi, H. et al. Árvores exóticas no Brasil: madeiras, ornamentais e aromáticas. Nova Odessa: Instituto Plantarum, 2003. 368 p.

Maloney, T. M. Modern particleboard \& dry-process fiberboard. San Francisco: Miller Freeman, 1993. 681 p.

Melo, R. R. et al. Avaliação das propriedades físico-mecânicas de painéis aglomerados de Eucalyptus grandis colados com ureiaformaldeído e tanino-formaldeído. Floresta, v. 40, n. 3, p. 497-506, 2010. DOI: $10.5380 /$ rf.v40i3.18911.

Momentive Química do Brasil. Cascamite (TM) MDP 1212. Ficha de Informações de Segurança de Produtos Químicos, Curitiba, 2012. $11 \mathrm{p}$.

Moslemi, A. A. Particleboard: volume 1: materials. London: Southern Illinois University Press, 1974. 244 p.
Napoli, L. M. et al. Propriedades físicas da madeira e de painéis aglomerados produzidos com misturas de espécies florestais. Floresta, v. 43, n. 3, p. 475-484, 2013. DOI: 10.5380/rf.v43i3.26204.

Sanches, F. L. et al. Resistência de painéis aglomerados produzidos com mistura de madeira de espécies florestais tradicionais e não tradicionais. Ciência Florestal, v. 26, n. 2, p. 559-569, 2016. DOI: 10.5902/1980509822756.

Tanac, S. A. \& Phenotan, A. G. Adesivo para aglomerados: catálogo técnico. Montenegro: [s.n.], 2014. 6 p.

Trianoski, R. et al. Utilização da madeira de Cryptomeria japonica para produção de painéis aglomerados. Scientia Forestalis, v. 41, n. 97, p. $57-64,2013$.

Trianoski, R. et al. Viabilidade da utilização de Acrocarpus fraxinifolius em diferentes proporções com Pinus spp. para produção de painéis aglomerados. Scientia Florestalis, v. 39, n. 91, p. 343-350, 2011.

Vale, A. T. et al. Caracterização e uso de madeiras de galhos de árvores provenientes da arborização de Brasília, DF. Ciência Florestal, v. 15, n. 4, p. 411-420, 2005. DOI: 10.5902/198050981878. 